\title{
OPEN SARS-CoV-2 viability on sports equipment is limited, and dependent on material composition
}

Thomas Edwards ${ }^{1}$, Grant A. Kay ${ }^{1}$, Ghaith Aljayyoussi ${ }^{1}$, Sophie I. Owen ${ }^{1}$, Andy R. Harland ${ }^{2}$, Nicholas S. Pierce ${ }^{3}$, James D. F. Calder ${ }^{4,5}$, Tom E. Fletcher ${ }^{6}$ \& Emily R. Adams ${ }^{1 凶}$

The control of the COVID-19 pandemic in the UK has necessitated restrictions on amateur and professional sports due to the perceived infection risk to competitors, via direct person to person transmission, or possibly via the surfaces of sports equipment. The sharing of sports equipment such as tennis balls was therefore banned by some sport's governing bodies. We sought to investigate the potential of sporting equipment as transmission vectors of SARS-CoV-2. Ten different types of sporting equipment, including balls from common sports, were inoculated with $40 \mu$ droplets containing clinically relevant concentrations of live SARS-CoV-2 virus. Materials were then swabbed at time points relevant to sports $(1,5,15,30,90 \mathrm{~min})$. The amount of live SARS-CoV-2 recovered at each time point was enumerated using viral plaque assays, and viral decay and half-life was estimated through fitting linear models to log transformed data from each material. At one minute, SARS-CoV-2 virus was recovered in only seven of the ten types of equipment with the low dose inoculum, one at five minutes and none at $15 \mathrm{~min}$. Retrievable virus dropped significantly for all materials tested using the high dose inoculum with mean recovery of virus falling to $0.74 \%$ at $1 \mathrm{~min}, 0.39 \%$ at $15 \mathrm{~min}$ and $0.003 \%$ at $90 \mathrm{~min}$. Viral recovery, predicted decay, and half-life varied between materials with porous surfaces limiting virus transmission. This study shows that there is an exponential reduction in SARS-CoV-2 recoverable from a range of sports equipment after a short time period, and virus is less transferrable from materials such as a tennis ball, red cricket ball and cricket glove. Given this rapid loss of viral load and the fact that transmission requires a significant inoculum to be transferred from equipment to the mucous membranes of another individual it seems unlikely that sports equipment is a major cause for transmission of SARS-CoV-2. These findings have important policy implications in the context of the pandemic and may promote other infection control measures in sports to reduce the risk of SARS-CoV-2 transmission and urge sports equipment manufacturers to identify surfaces that may or may not be likely to retain transferable virus.

Public health interventions to control the COVID-19 pandemic in the UK have necessitated restrictions in social mixing, with both amateur and professional sports either prohibited, or allowed with considerable infection control measures in place ${ }^{1}$. It has been estimated that up to $44 \%$ of transmission occurs prior to symptom onset, when viral loads are highest ${ }^{2}$, meaning people are unaware of the infection and will continue in their daily activities, including sports participation. All team sport in the UK was postponed and subsequently cancelled from mid-March 2020 and although a staged return to elite sport was enabled from $\mathrm{April}^{3}$, there was concern that participation in community sport could risk disease transmission. Limited return in team sport with strict hygiene measures at sports grounds and rule changes for some contact sports were imposed.

\footnotetext{
${ }^{1}$ Department of Tropical Disease Biology, Liverpool School of Tropical Medicine, Pembroke Place, Liverpool L3 50A, UK. 'Wolfson School of Mechanical, Manufacturing and Electrical Engineering, Loughborough University, Ashby Road, Loughborough LE11 3TU, UK. ${ }^{3}$ England and Wales Cricket Board and National Centre for Sport and Exercise Medicine, Loughborough University, Loughborough LE11 3TU, UK. ${ }^{4}$ Fortius Clinic, London W1U 2EU, UK. ${ }^{5}$ Department of Bioengineering, Imperial College London, London SW7 2AZ, UK. ${ }^{6}$ Department of Clinical Sciences, Liverpool School of Tropical Medicine, Pembroke Place, Liverpool L3 50A, UK. ${ }^{\boxplus e m a i l}$ : Emily.adams@ Istmed.ac.uk
} 


\begin{tabular}{|l|l|l|}
\hline Equipment type & Standard & Surface material \\
\hline Cricket glove (palm) & BS 6183-4: 2001* & Calf leather \\
\hline Control & Stainless steel & \\
\hline Football & FIFA Quality Pro. Law 2: IFAB Laws of the Game & Thermoplastic Polyurethane (TPU) \\
\hline Golf ball & $\begin{array}{l}\text { Part 4, The Equipment Rules, USGA. Named on list of } \\
\text { conforming balls, USGA, R\&A }\end{array}$ & SurlynTM ionomer resin \\
\hline Gym pit foam & $\mathrm{n} / \mathrm{a}$ & Polyurethane (PU) foam (open cell) \\
\hline Horse saddle & $\mathrm{n} / \mathrm{a}$ & Polyurethane (PU) \\
\hline Red Cricket ball (unused) & BS 5993:1994* Law 4, The Laws of Cricket, MCC & Bovine leather burnished with synthetic grease \\
\hline Rugby ball & Law 2: Ball, World Rugby Laws & Rubberised polyester (PES) \\
\hline Tennis Ball & ITF Approved, Rule 3, ITF Rules of Tennis & Raised Wool/Nylon woven cloth \\
\hline White Cricket ball (unused) & $\begin{array}{l}\text { BS 5993:1994* } \\
\text { Law 4, The Laws of Cricket, MCC }\end{array}$ & Bovine leather with nitrocellulose coating \\
\hline
\end{tabular}

Table 1. Equipment and materials used in the study. ${ }^{\star}$ Indicates standards available to certify such products, however it is not known whether product was subject to standard testing.

The major risk of SARS-CoV-2 transmission during team sports is likely direct player to player transmission via respiratory droplets ${ }^{4}$, either during play or socially before and after the game. During non-contact sports such as cricket and soccer the risk of transmission is considered very low because only fleeting incursions of social distancing are seen ${ }^{5}$. Few amateur sporting events have been linked to SARS-CoV-2 transmission. A Danish study on professional football reported that during a $90 \mathrm{~min}$ match the average time any player spent within $1.5 \mathrm{~m}$ of another was 87.8 seconds $^{6}$, and a study of the return of competitive football in Germany concluded that training and matches may be carried out safely during the SARS-CoV-2 pandemic ${ }^{7}$. Careful evaluation of elite level contact sports such as rugby failed to demonstrate evidence of transmission during the course of playing and training.

Although there is uncertainty about the role of fomites in SARS-CoV-2 transmission ${ }^{9}$, equipment which is commonly shared in sports was considered as a potentially important route of transmission. In June 2020 the UK Prime Minister Boris Johnson stated in the House of Commons that cricket balls are a "natural vector" of coronavirus provoking a lively debate in the press on the safety of opening community sports. When team sports were re-introduced, so too were recommendations to reduce the sharing of sports equipment such as tennis balls. Whilst the viability of virus on a variety of surfaces has been demonstrated, transmission requires the deposition of virus onto a surface, then the transfer of enough virus to cause an infection from that surface to the mucus membranes of another person. Viral shedding into the environment has been demonstrated during SARS-CoV-2 infections, for example the rooms of hospitalised SARS-CoV-2 patients can be heavily contaminated with SARSCoV-2, including frequently touched surfaces such as sinks and door handles ${ }^{10}$. This is thought to be from the spread of respiratory droplets via breathing, sneezing and coughing ${ }^{11}$, and the transfer of SARS-CoV-2 to objects from the hands of patients has been documented ${ }^{12}$. The minimum infectious dose of SARS-CoV-2 is currently unknown ${ }^{13}$, which makes quantifying the required viral load for transmission difficult.

It has been hypothesised that because physical sports lead to increased respiration, deep exhalation is likely to increase the expulsion of droplets or aerosols containing infectious particles which may contaminate sports equipment. Additionally, spitting is common in some team sports such as football and rugby and saliva has been used to shine cricket balls. Secretions from the upper respiratory tract have the potential to carry high viral loads ${ }^{14}$, which could then be transferred onto materials such as clothing or balls. Studies on viral stability on sporting equipment are limited. Pelisser et al. reported that inactivated SARS-CoV-2 may be detected by RT-qPCR from the surfaces of cricket balls up to one hour past the inoculation ${ }^{15}$, although viral viability could not be determined using this approach. Determining the potential for SARS-CoV-2 transmission whilst sharing sports equipment is crucial when producing guidelines to mitigate risks for return of community and elite team sports. This study [SARS-CoV-2 Transmission Risk from sports Equipment (STRIKE)] aimed to quantify the recoverable live virus from droplets of viable SARS-CoV-2 suspensions deposited onto a variety of sporting equipment, over a time frame relevant to sporting activity.

\section{Methods}

Materials. Sporting materials were selected from the materials collection at the Sports technology Institute at Loughborough University (Table 1). These included commonly handled objects from popular sports, such as rugby, football and tennis balls. All materials were unused prior to testing. Materials frequently shared between participants were prioritised due to a greater potential as transmission vectors. Materials were cut into $2 \mathrm{~cm}$ diameter disks using a metal hole punch. The red cricket ball was not cut into disks, and instead used whole, due to difficulties retaining surface integrity during removal. Materials were not sterilised prior to inoculation, so as not to affect the surface coatings, and antibiotics in the media were relied upon to avoid contamination during cell culture. Steel disks were purchased (Lasermaster, UK) for use as a control surface.

Material inoculation. Materials were inoculated with a $40 \mu$ droplet of Dulebecco's Modified Eagles Medium (DMEM) containing a high $\left(5.4 \times 10^{4}\right.$ plaque-forming units $\left.(\mathrm{PFU})\right)$ or low $\left(5.4 \times 10^{2} \mathrm{PFU}\right)$ concentra- 
tion of quantified live SARS-CoV-2 virus (isolate REMRQ0001/Human/2020/Liverpool). Inoculum concentrations were chosen as representing the upper and lower quartile of viral loads in symptomatic patients ${ }^{15}$. All work with live virus took place under BSL3 conditions in a Class 2 biological safety cabinet. Materials were inoculated on the outward facing surface, and care was taken to ensure the inoculum did not run off the material during the inoculation. Triplicate pieces of each material were inoculated for the following time points: 1, 5, 15, 30, 90 min. At each time point the materials were swabbed using dry cotton swabs (Copan, Italy), and added to $400 \mu \mathrm{l}$ of DMEM. A standardised swabbing technique was employed for each sample to reduce variation, with the swab being dragged upwards for two seconds and sideways for two seconds. The tubes containing the swabs were vortexed for $5 \mathrm{~s}$, and then serially diluted ten-fold for three dilutions, in DMEM. During the study period the laboratory temperature and humidity were $22.1{ }^{\circ} \mathrm{C} \pm 1.6$ and $52 \%$ relative humidity $\pm 3.8 \%$.

Cell culture. Cultures of VERO E6 cells (C1008; African green monkey kidney cells, European Collection of Authenticated Cell Cultures 85,020,206) were maintained in T75 cell culture flasks (Corning, US) in Dulbecco's Modified Eagles Medium (DMEM) supplemented with $4.5 \mathrm{~g} / \mathrm{L}$ glucose and L-Glutamine (Lonza, US), $10 \%$ foetal bovine serum (Sigma, US) and 50 units per $\mathrm{ml}$ of penicillin/streptomycin (Gibco, US), at $37.5^{\circ} \mathrm{C}+5 \% \mathrm{CO} 2$. Cells for plaque assays were detached from the monolayer using $2 \mathrm{ml} 1 \times \operatorname{trypsin}$-EDTA (Sigma, US) and $500 \mu \mathrm{l}$ was seeded into 24 well microtitre plates (Corning, US) at a density of 250,000 cells $/ \mathrm{ml}$. Plates were incubated for $24 \mathrm{~h}$ at $37.5^{\circ} \mathrm{C}+5 \% \mathrm{CO}_{2}$ and used for downstream plaque assays if judged to be $>95 \%$ confluent by microscopy.

Viral plaque assays. Viral plaque assays were carried out using VERO E6 cells in 24 well microtitre plates. Media was aspirated from the microtitre plates, and $40 \mu \mathrm{l}$ of media from the swabs and further dilutions were added to triplicate wells with $160 \mu \mathrm{l}$ of DMEM $2 \%$ FBS. Microtitre plates were incubated for $1 \mathrm{~h}$ at $37.5^{\circ} \mathrm{C}+5 \%$ $\mathrm{CO}_{2}$ to ensure viral infection. Plates were then removed from the incubator and overlaid with a $1.1 \%$ suspension of cellulose (Sigma, UK) in DMEM 2\% FBS, and incubated again under the same conditions for $72 \mathrm{~h}$. Plates were then removed from the incubation, fixed with $100 \%$ formaldehyde for one hour, and stained with $1 \mathrm{ml} /$ well of $0.25 \%$ crystal violet solution. After staining for $1 \mathrm{~min}$, plates were gently washed with water, then air dried for $>3 \mathrm{~h}$. Viral plaques were then visually counted for each well. The total PFU retrieved from the swab was then back calculated from the viral plaque counts from the $40 \mu \mathrm{l}$ media tested. A schematic of the methods is shown in Fig. S1 (produced using BioRender, https://biorender.com/).

Outcomes. All individual plaque counts for each material/time point swab were used to analyse the viral recovery from each material. Readings below the limit of quantitation (BLQ) were assumed to be equal to the BLQ levels/2. To characterise SARS-CoV-2 retained on different materials, a dynamic approach was used to measure the time-reduction course of virus. This was achieved by estimating viral decay half-life through linear models to log transformed PFU data on each material. The model assumed a single-phase decay profile on all materials over time. Each material was assumed to have a different intercept and slope as the materials varied widely in the observed initial levels of virus at the first minute.

Statistical analysis. Linear fitting was achieved through the $l m$ function in R. After generating a slope and intercept for each material, simulations were performed based on the estimates for each of these parameters and their covariance using R. 500 simulations were performed for each material and their 5-95 percentiles were plotted against the observed data. To estimate the overall exposure to virus over time for each material, the area under the curve (AUC) of the time-virus simulated profile was estimated for each of the 500 simulations and compared as the primary measure describing the overall exposure of each material to the virus over time. Simulated AUCs for each material were compared statistically using non-parameteric pairwise comparisons using Wilcoxon rank sum test. Materials were ranked based on AUC in comparison to the control material on all reported graphs. Simulated half-life and AUC data are presented as box and whiskers plots displaying the 5-95 percentiles of the 500 simulated profiles for each material.

Patient and public involvement statement. As this was solely a laboratory study we did not involve any patients or members of the public in the study design.

\section{Results}

At the one-minute time point SARS-CoV-2 was only detected in 7/10 materials when using the low inoculum dose (recovered virus ranging from 10 to 40 virions) (Fig. 1). At five minutes virus was detected on the horse saddle alone (20 virions) and no virus was detected on any material at $15 \mathrm{~min}$. The model-predicted decay for the low inoculum is shown in Fig. 2 and the AUC and predicted half-life for the low inoculum were lower than that of the high inoculum (Fig. 3).

For the high inoculum dose, virus was recoverable from every material except the cricket glove at the oneminute time point (Fig. 1) but the viral titre reduced from $5.4 \times 10^{4}$ to an average of $3.7 \times 10^{2}$ (range of $1 \times 10^{3}$ to 0 ) virions. The highest recovery was obtained from the rugby ball, steel control disks and horse saddle with the lowest viral titres retrieved were from absorbent materials such as the cricket glove, red cricket ball and tennis ball. Viral recovery reduced over time for all materials tested and no virus could be retrieved at $90 \mathrm{~min}$, except for the horse saddle and rugby ball, although viral levels had reduced to 2 and 12 virions, respectively. The mean recovery reduced significantly at the one, five, 15 , and 30 -min time points for all materials $(\mathrm{P}=0.0137,0.0185$, 0.0174 , and 0.0117 , respectively). The mean recovery of virus fell across all materials to $0.74 \%$ at one minute, $0.39 \%$ at $15 \mathrm{~min}$ and $0.003 \%$ at $90 \mathrm{~min}$ (Fig. S2). 


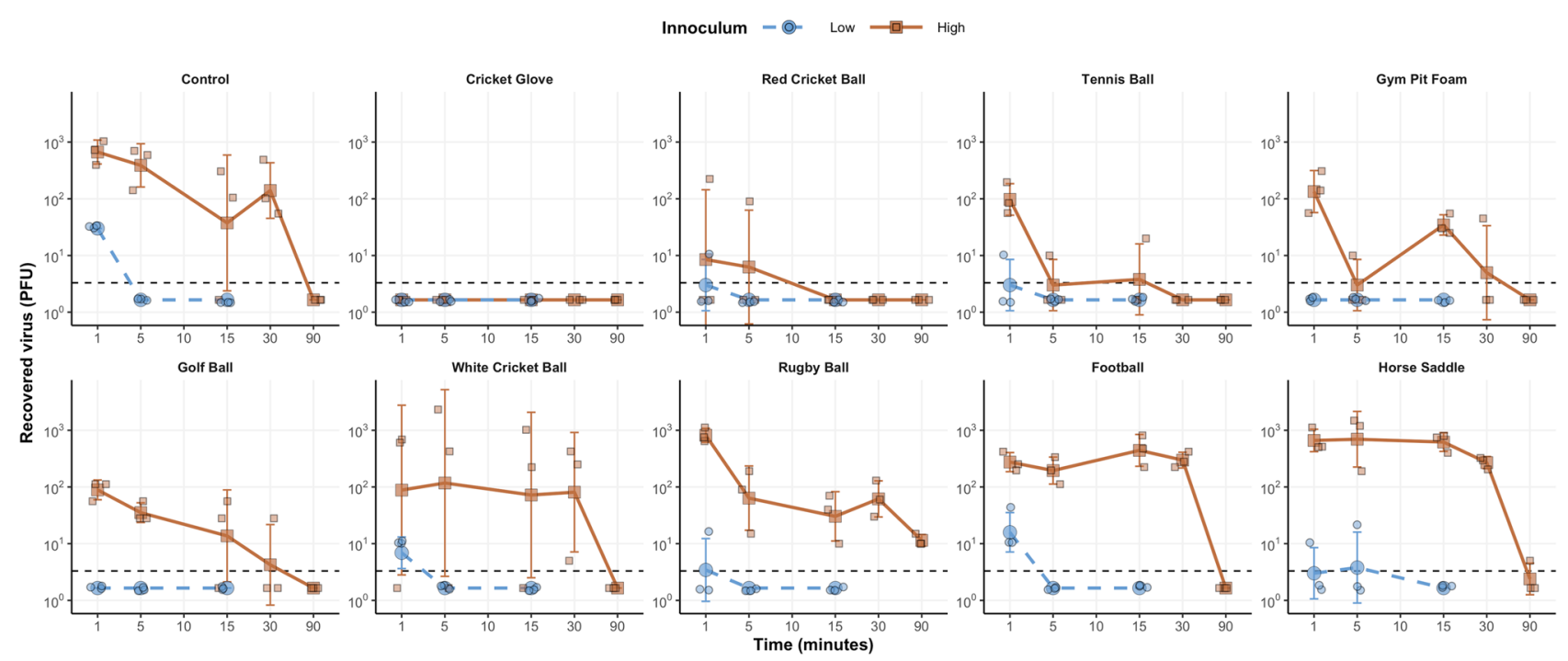

Figure 1. Recovered virus from all materials inoculated with $5.4 \times 10^{2} \mathrm{PFU}$ (low inoculum, blue line) and $5.4 \times 10^{4} \mathrm{PFU}$ (high inoculum, orange line) across the $90 \mathrm{~min}$ sampling time, including the control sample (steel disk). Large cirlcesrepresent the geometric mean of three replicates (shown as small circles) and Error bars indicate the geometric standard deviations.
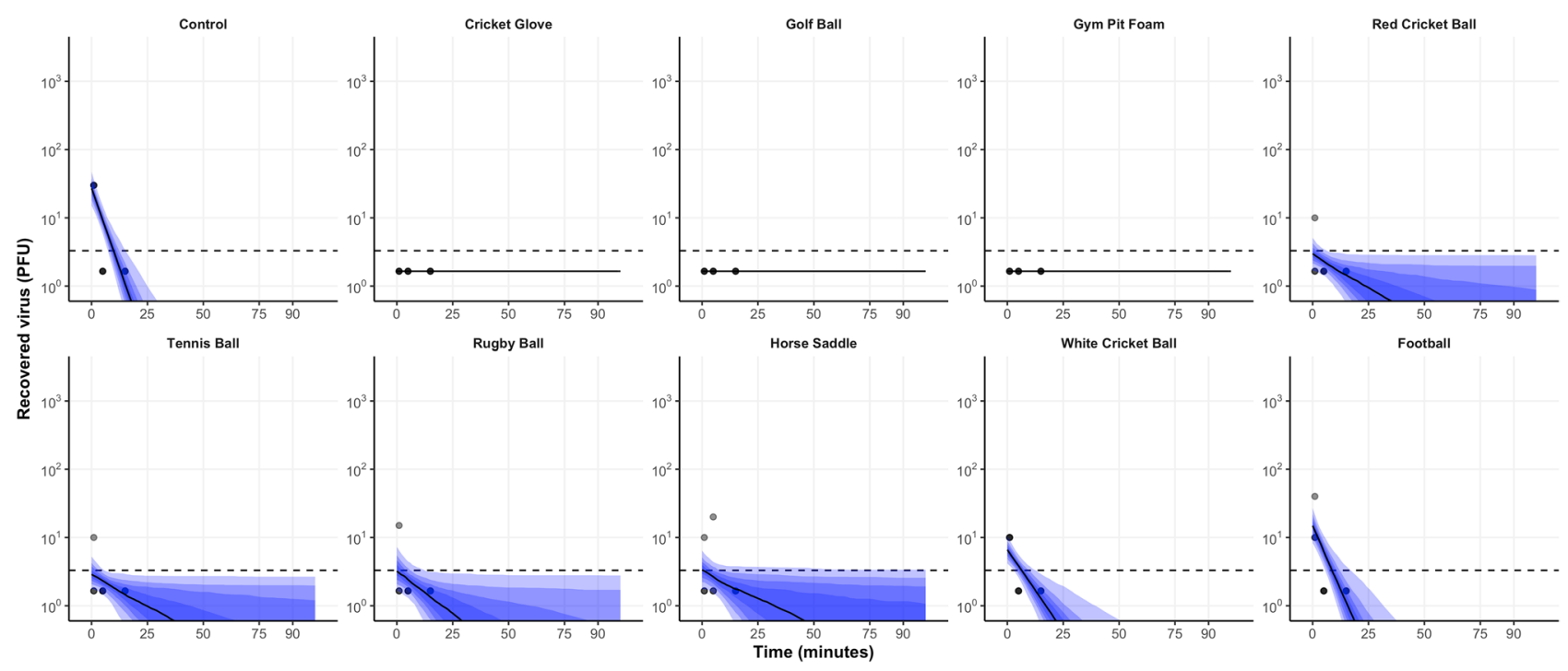

Figure 2. The predicted median decay of viral titres (solid black line) with 5-95 percentiles (shaded red areas) overlaid with observed PFU (grey circles) from all materials inoculated with $5.4 \times 10^{2} \mathrm{PFU}$ (low inoculum) using a linear regression model on log-transformed data.

Exponential viral decay was predicted from the linear regression models for all surfaces tested, indicated by a straight line of decay on the $\log ^{10}$ viral PFU scale (Fig. 4). Data from the white cricket ball was more varied, with subsequent wider ranges in possible decay rates. The estimated mean half-life of deposited virus after the one-minute time point ranges from $24 \mathrm{~min}$ (control) to $60 \mathrm{~min}$ (golf ball) (Fig. 5). The area under the curve (AUC) analysis takes into account the initial decrease in recoverable virus and ranks the surfaces in terms of transmissibility of SARS-CoV-2, from porous materials such as the cricket ball to less porous materials such as the horse saddle. Analyses using Wilcox non-parametric test showed that AUCs simulated for different materials are statistically different with $\mathrm{p}<0.001$ with the horse saddle containing the highest amount of virus over time and the cricket glove the lowest.

\section{Discussion}

This laboratory-based study demonstrates an exponential reduction in detectable live SARS-CoV-2 virions for all inoculated sports equipment over a short time period. The study focussed on materials that are likely to be shared or touched by multiple people during individual or team sports, including balls from a range of sports, plus cricket gloves, gymnastic spit foam, and a racing horse saddle. The low inoculum (representing droplets 

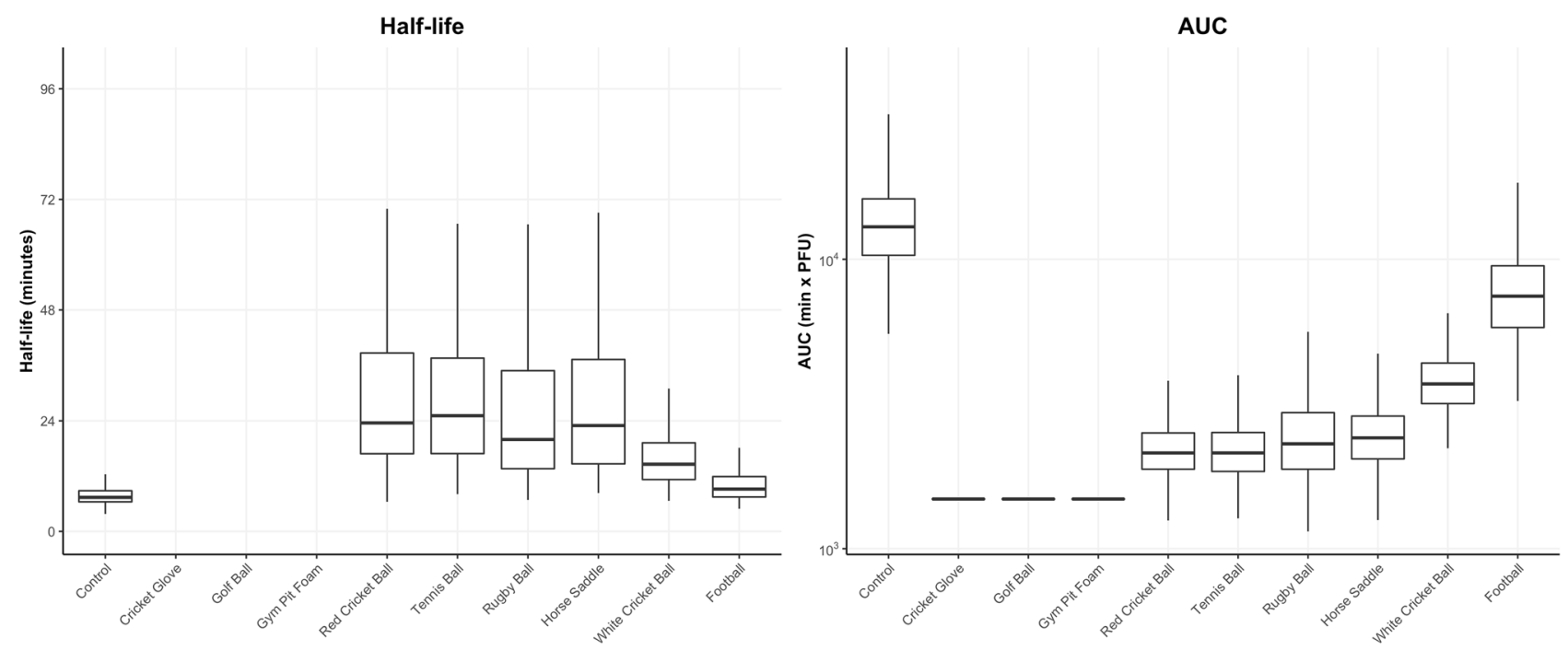

Figure 3. Box and whiskers plots representing the Half-life and area under the curve (AUC) distribution of 500 generated profiles for each material inoculated with SARS-CoV-2 at 5.4 $\times 10^{2} \mathrm{PFU}$ (low inoculum).
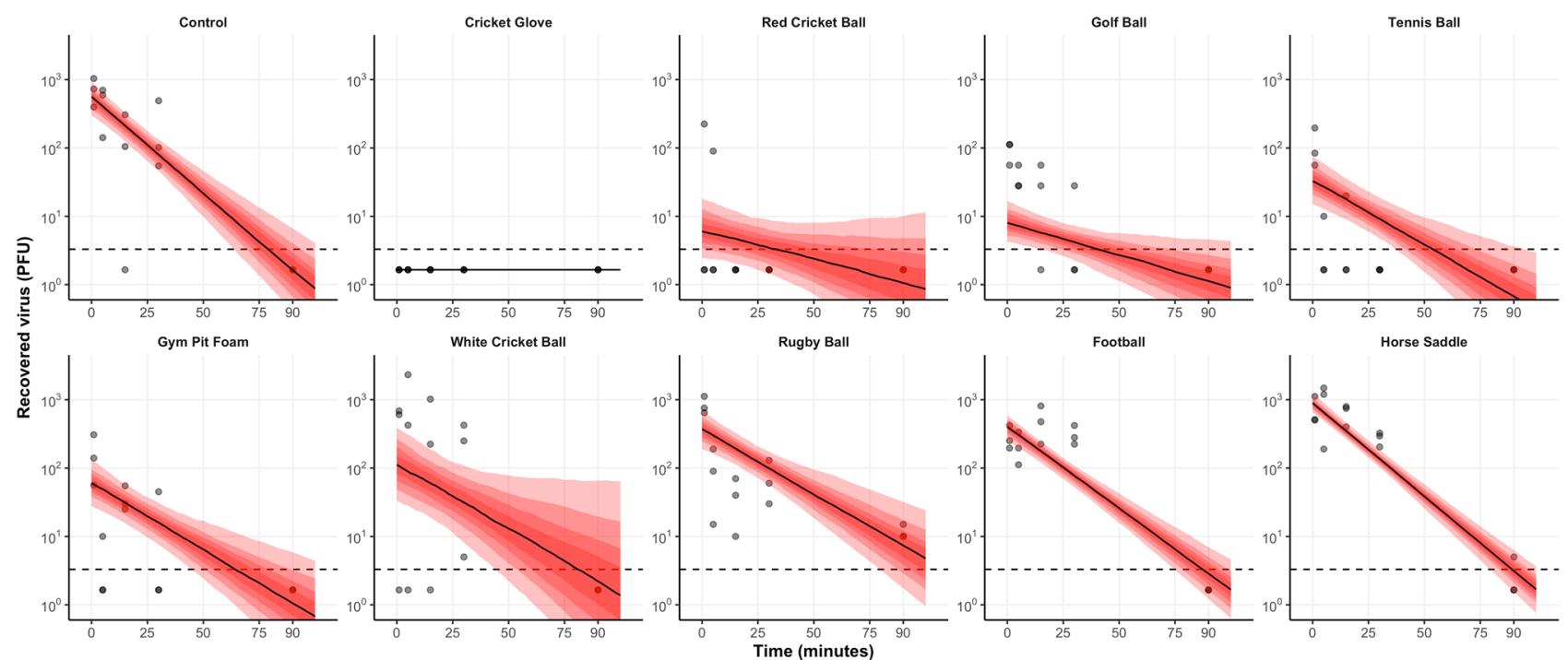

Figure 4. The predicted median decay of viral titres (solid black line) with 5-95 percentiles (shaded red areas) overlaid with observed PFU (grey circles) from all materials inoculated with $5.4 \times 10^{4} \mathrm{PFU}$ (high inoculum) using a linear regression model on log-transformed data.

from the lower quartile of viral loads in symptomatic patients) ${ }^{16}$ could only be detected on the horse saddle at five minutes and no virus could be detected on any material at $15 \mathrm{~min} .0 .74 \%$ of virus was recoverable at one minute in the high inoculum (representing droplets from the higher quartile of viral loads), $0.39 \%$ at 15 min and just $0.003 \%$ at $90 \mathrm{~min}$. This indicates that transfer of sufficient virus from fomites is unlikely from individuals with lower viral loads. As the viral inoculum dried over time, less virus was recoverable, matching previous studies on inanimate surfaces ${ }^{17}$.

The contribution of fomites to the transmission of SARS-CoV-2 is controversial ${ }^{18}$. Wilson et al. ${ }^{19}$ used a Monte Carlo simulation to perform a quantitative microbial assessment of the risk of infection from fomites, and found a lower than $1 / 10,000$ infection risk from surfaces infected with a range of 1 to 10,000 genome copies/cm, supporting the potentially limited role of fomites in SARS-CoV-2 transmission. In addition, it should be noted that in certain sports, equipment such as balls may come in contact with crowds where unknown viral load may be encountered. Participants in sports are likely to be asymptomatic, however viral loads in this sub group appears to be similar to those in symptomatic patients ${ }^{20}$. A South Korean cohort study of 303 non-hospitalised SARSCoV-2 positive patients (193 symptomatic/110 asymptomatic) found no significant difference in RT-qPCR Ct values between the groups ${ }^{21}$. Quantification of the viral load that may be transferred from an individual with SARS-CoV-2 infection onto sports equipment has not been evaluated but this study used previously reported concentrations seen in respiratory tract secretions. 

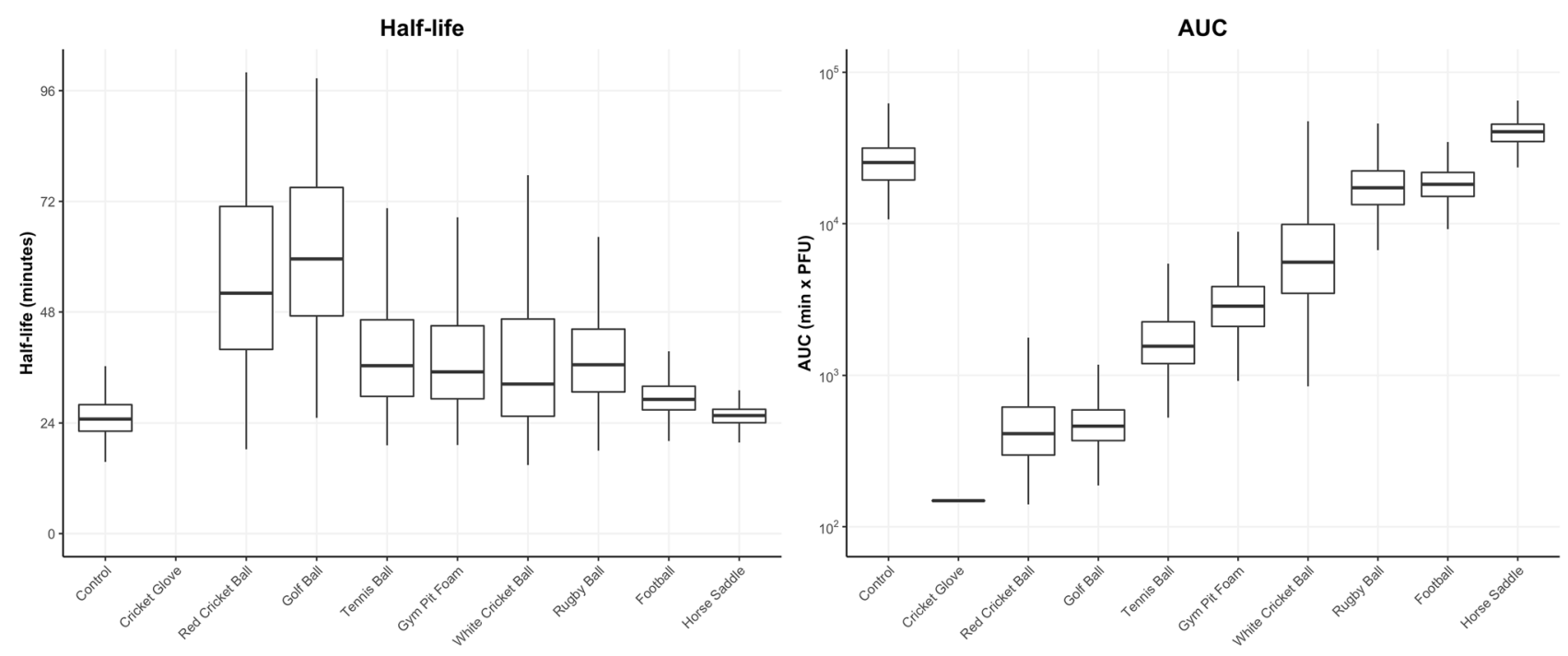

Figure 5. Box and whiskers plots representing the Half-life and area under the curve (AUC) distribution of 500 generated profiles for each material inoculated with SARS-CoV-2 at 5.4 $\times 10^{4} \mathrm{PFU}$ (high inoculum).

The effect of material composition on SARS-CoV-2 transfer. We found that viral recovery was reduced by absorbent materials such as leather (red cricket ball and cricket glove) and polyurethane foam (gym mat foam). Despite the white and red cricket ball surfaces both being composed of bovine leather, the different coatings used to finish the surfaces (synthetic grease on the red ball, nitrocellulose on the white ball) had a noticeable effect on viral recovery, with the red ball having a lower level. These properties were observed in unused cricket balls. It is expected that with use cricket balls will lose the coatings and may become more porous. Previous studies have shown that viruses such as avian influenza have shorter recovery times from porous materials or open-cell foam structures ${ }^{22}$, presumably as viral particles are trapped inside and are not easily transferred during contact. The physiochemical interactions between the viral capsid and the material are also likely to impact the viral viability and transfer from the material ${ }^{23}$, and therefore the hydrophobicity and electrostatic properties of polymer surfaces may be important in their role as fomites. The observation that porous materials result in reduced viral recovery and transmission risk can be used to prioritise materials for within-game cleaning or swapping, and focus cleaning efforts to reduce their effect on sporting events.

Limitations. All experiments were carried under a single temperature and humidity, two parameters known to affect SARS-CoV-2 viability ${ }^{24}$. Sports are played under different conditions due to seasonality and whether they take place in or outdoors. A more accurate assessment would include these variables. The minimum infectious dose of SARS-CoV-2 remains unknown ${ }^{13}$, and this makes it difficult to extrapolate the amount of virus on a surface necessary for transmission. The prospect of future human challenge models may provide this data ${ }^{25}$.

Our methodology employed a dry swab to retrieve the virus from the surfaces, in order to best replicate the transfer onto a player's body or clothing. Higher viral recovery, and possibly less variation between replicates, would have been achieved by directly adding media to absorb virus ${ }^{26}$ or by using a wet swab ${ }^{27}$. However, this would not replicate the real-world conditions that the experiments were designed to assess. The recovery rate of dry swabs varies, but has been estimated as $32-38 \%$ for recovering MS2 phage from steel surfaces, depending on the elution media ${ }^{28}$. Therefore, more virus is likely to be present on the materials than our results infer.

This was a laboratory study, and further in-game behavioural studies are required to show frequency of potential transmission events to quantify risk. In practice many items of sports equipment are not routinely handed from person to person but instead rub against or collide with implements, other parts of the body, the ground and other sports infrastructure, presumably further reducing viral load. This is illustrated by a study showing SARS-CoV-2 RNA was not detectable from inoculated cricket balls after wiping, rolling, or bouncing on the floor ${ }^{15}$. We tested un-used sports equipment for the study, and material surfaces may change after short- or long-term usage, potentially affecting viral adherence and surface transmission.

\section{Conclusions}

This study demonstrates the rapid decay in transmissible SARS-CoV-2 virus on several types of sports equipment and given the uncertainty of the role of fomites in the transmission of virus it is likely that close contact with other players either during play or pre/post-match travel and socialising is more important as a mode of spreading the virus. This has implications for policymakers introducing control measures during the reopening of sports. The differences in transfer seen between types of sports equipment may also direct the engineering of materials that retain and absorb virus, as opposed to hydrophobic materials where viral transfer is greater. 
Received: 8 March 2021; Accepted: 17 December 2021

Published online: 26 January 2022

\section{References}

1. Flynn, D. et al. COVID-19 pandemic in the United Kingdom. Health Policy Technol. 9(4), 673-691 (2020).

2. He, X. et al. Temporal dynamics in viral shedding and transmissibility of COVID-19. Nat. Med. 26(5), 672-675 (2020).

3. Kemp, S. et al. Sports medicine leaders working with government and public health to plan a 'return-to-sport' during the COVID19 pandemic: The UK's collaborative five-stage model for elite sport. Br. J. Sports Med. 55, 4-5 (2020).

4. The Lancet Respiratory M. COVID-19 transmission;up in the air. Lancet Resp. Med. 8, 1159 (2020).

5. Harland, A. The potential for airborne transmission of SARS-CoV-2 in sport; a cricket case study. Int. J. Sports Med. 42, 407-418 (2020).

6. Knudsen, N. S., Thomasen, M. M. \& Andersen, T. B. Spread of virus during soccer matches. medRxiv 25, 1 (2020).

7. Meyer, T. et al. Successful return to professional men's football (soccer) competition after the COVID-19 shutdown: A cohort study in the German Bundesliga. Br. J. Sports Med. 55, 62-65 (2021).

8. Jones, B. et al. SARS-CoV-2 transmission during rugby league matches: Do players become infected after participating with SARSCoV-2 positive players?. Br. J. Sports Med. 55(14), 807-813 (2021).

9. Mondelli, M. U., Colaneri, M., Seminari, E. M., Baldanti, F. \& Bruno, R. Low risk of SARS-CoV-2 transmission by fomites in reallife conditions. Lancet Infect. Dis 21, e112 (2021).

10. Ong, S. W. X. et al. Air, surface environmental, and personal protective equipment contamination by severe acute respiratory syndrome coronavirus 2 (SARS-CoV-2) from a symptomatic patient. JAMA 323(16), 1610-1612 (2020).

11. Dhand, R. \& Li, J. Coughs and sneezes: Their role in transmission of respiratory viral infections, including SARS-CoV-2. Am. J. Respir. Crit. Care Med. 202(5), 651-659 (2020).

12. Salido, R. A. et al. Handwashing and detergent treatment greatly reduce SARS-CoV-2 viral load on halloween candy handled by COVID-19 patients. mSystems 5(6), e01074-20 (2020).

13. Cevik, M., Kuppalli, K., Kindrachuk, J. \& Peiris, M. Virology, transmission, and pathogenesis of SARS-CoV-2. BMJ 371, 33862 (2020).

14. Byrne, R. L. et al. Saliva alternative to upper respiratory swabs for SARS-CoV-2 diagnosis. Emerg. Infect. Dis. 26(11), 2770-2771 (2020).

15. Pelisser, M. et al. Sports balls as potential SARS-CoV-2 transmission vectors. Public Health Pract. 1, 100029 (2020)

16. Zheng, S. et al. Viral load dynamics and disease severity in patients infected with SARS-CoV-2 in Zhejiang province, China, January-March 2020: Retrospective cohort study. BMJ 369, m1443 (2020).

17. Kratzel, A. et al. Temperature-dependent surface stability of SARS-CoV-2. J. Infect. 81(3), 452-482 (2020).

18. Goldman, E. Exaggerated risk of transmission of COVID-19 by fomites. Lancet Infect. Dis. 20(8), 892-893 (2020).

19. Wilson, A. M., Weir, M. H., Bloomfield, S. F., Scott, E. A. \& Reynolds, K. A. Modeling COVID-19 infection risks for a single handto-fomite scenario and potential risk reductions offered by surface disinfection. Am. J. Infect. Control 49(6), 846-848 (2020).

20. $\mathrm{Ra}, \mathrm{S}$. H. et al. Upper respiratory viral load in asymptomatic individuals and mildly symptomatic patients with SARS-CoV-2 infection. Thorax 76, 1-61 (2020).

21. Lee, S. et al. Clinical Course and molecular viral shedding among asymptomatic and symptomatic patients with SARS-CoV-2 infection in a community treatment center in the Republic of Korea. JAMA Inter. Med. 180(11), 1447-1452 (2020).

22. Tiwari, A., Patnayak, D. P., Chander, Y., Parsad, M. \& Goyal, S. M. Survival of two avian respiratory viruses on porous and nonporous surfaces. Avian Dis. 50(2), 284-287 (2006).

23. Xue, X., Ball, J. K., Alexander, C. \& Alexander, M. R. All surfaces are not equal in contact transmission of SARS-CoV-2. Matter 3(5), 1433-1441 (2020).

24. Biryukov, J. et al. Increasing temperature and relative humidity accelerates inactivation of SARS-CoV-2 on surfaces. $m S p h e r e$ (4), e00441-e520 (2020).

25. Kirby, T. COVID-19 human challenge studies in the UK. Lancet Resp. Med. 8(12), e96 (2020).

26. van Doremalen, N. et al. Aerosol and surface stability of SARS-CoV-2 as compared with SARS-CoV-1. N. Engl. J. Med. 382(16), 1564-1567 (2020).

27. Organisation, W. H. Surface Sampling of Coronavirus Disease (COVID-19): A Practical "How To" Protocol for Health Care and Public Health Professionals (WHO, 2020).

28. Julian, T. R., Tamayo, F. J., Leckie, J. O. \& Boehm, A. B. Comparison of surface sampling methods for virus recovery from fomites. Appl. Environ. Microbiol. 77(19), 6918-6925 (2011).

\section{Author contributions}

J.D.F.C., T.E.F., and E.R.A. conceptualised the study. T.E., G.A.K., S.I.O., A.R.H., N.S.P., J.D.F.C., T.E.F. and E.R.A. contributed to the experimental design and methodology. T.E., G.A.K., and S.I.O. carried out laboratory experiments. T.E. and G.A. contributed to data curation and analysis. T.E., A.R.H., N.S.P., J.D.F.C. and E.R.A. wrote and edited the first draft of the manuscript. All authors reviewed and edited the final manuscript.

\section{Funding}

The study was funded by philanthropic donations and contributions from the UK National Governing Bodies of Sport. The funders had no input into the design, interpretation or reporting of the study.

\section{Competing interests}

NSP is employed in part by the England and Wales Cricket Board. All other authors declare no competing interests.

\section{Additional information}

Supplementary Information The online version contains supplementary material available at https:/doi.org/ 10.1038/s41598-022-05515-1.

Correspondence and requests for materials should be addressed to E.R.A.

Reprints and permissions information is available at www.nature.com/reprints.

Publisher's note Springer Nature remains neutral with regard to jurisdictional claims in published maps and institutional affiliations. 
(c) (i) Open Access This article is licensed under a Creative Commons Attribution 4.0 International cc) License, which permits use, sharing, adaptation, distribution and reproduction in any medium or format, as long as you give appropriate credit to the original author(s) and the source, provide a link to the Creative Commons licence, and indicate if changes were made. The images or other third party material in this article are included in the article's Creative Commons licence, unless indicated otherwise in a credit line to the material. If material is not included in the article's Creative Commons licence and your intended use is not permitted by statutory regulation or exceeds the permitted use, you will need to obtain permission directly from the copyright holder. To view a copy of this licence, visit http://creativecommons.org/licenses/by/4.0/.

(C) The Author(s) 2022 